\title{
Sperm counts and endocrinological markers of spermatogenesis in long-term survivors of testicular cancer
}

\section{Brydøy*,1,2, SD Fosså ${ }^{3,4}$, O Klepp ${ }^{5,6}$, RM Bremnes ${ }^{7,8}$, EA Wist ${ }^{4,9}$, T Bjøro ${ }^{4,10}$, T Wentzel-Larsen ${ }^{11,12,13}$ and O Dahl ${ }^{1,2}$, for the Norwegian Urology Cancer Group (NUCG) III study group}

'Section of Oncology, Institute of Medicine, University of Bergen, Bergen N-502I, Nonway; ${ }^{2}$ Department of Oncology, Haukeland University Hospital, Bergen N-502 I, Nonway; ${ }^{3}$ National Resource Center for Late Effects, Department of Oncology, Oslo University Hospital, Radiumhopitalet, Oslo N-03 I 0, Norway; ${ }^{4}$ Institute of Clinical Medicine, University of Oslo, Post box 117 I Blindern, Oslo N-0316, Norway; ${ }^{5}$ St Olav University Hospital, Post box 3250 Sluppen, Trondheim N-7006, Nonway; ${ }^{6}$ Norwegian University of Science and Technology, Trondheim N-7491, Nonway; ${ }^{7}$ Department of Oncology, University Hospital of North Nonway, Post box 13, Tromsø N-9038, Nonway; ${ }^{8}$ Institute of Clinical Medicine, University of Tromsø, Tromsø N-9037, Norway; ${ }^{9}$ Department of Oncology, Oslo University Hospital, Post box 4950 Nydalen, Oslo N-0424, Norway; ${ }^{10}$ Department of Medical Biochemistry, Division of Diagnostics and Intervention, Oslo University Hospital, Post box 4950, Oslo N-0424, Norway; "Centre for Clinical Research, Haukeland University Hospital, Bergen N-502I, Norway; ${ }^{12}$ Centre for Child and Adolescent Mental Health, Eastern and Southern Norway, Post box 4623, Nydalen, Oslo N-0405, Norway; ${ }^{13}$ Norwegian Centre for Violence and Traumatic Stress Studies, Kirkeveien 166, Oslo N-0450, Norway

BACKGROUND: The objective of this study was to assess markers of spermatogenesis in long-term survivors of testicular cancer (TC) according to treatment, and to explore correlations between the markers and associations with achieved paternity following TC treatment.

METHODS: In I I91 TC survivors diagnosed between 1980 and 1994, serum-follicle stimulating hormone (s-FSH; $n=119$ |), s-inhibin B $(n=44 \mathrm{l})$, and sperm counts (millions per $\mathrm{ml} ; n=342$ ) were analysed in a national follow-up study in 1998-2002. Paternity was assessed by a questionnaire.

RESULTS: At median II years follow-up, 44\% had oligo- (< I 5 millions per ml; 29\%) or azoospermia (I 5\%). Sperm counts and s-inhibin $\mathrm{B}$ were significantly lower and s-FSH was higher after chemotherapy, but not after radiotherapy (RT), when compared with surgery only. All measures were significantly more abnormal following high doses of chemotherapy (cisplatin (Cis) $>850 \mathrm{mg}$, absolute cumulative dose) compared with lower doses (Cis $\leqslant 850 \mathrm{mg}$ ). Sperm counts were moderately correlated with s-FSH ( -0.500 ), s-inhibin $B(0.455)$, and s-inhibin B:FSH ratio $(-0.524$; all $P<0.00 I)$. All markers differed significantly between those who had achieved post-treatment fatherhood and those with unsuccessful attempts.

CONCLUSION: The RT had no long-term effects on the assessed markers of spermatogenesis, whereas chemotherapy had. At present, the routine evaluation of s-inhibin $B$ adds little in the initial fertility evaluation of TC survivors.

British Journal of Cancer (2012) 107, I833-1839. doi:I0.1038/bjc.2012.47I www.bjcancer.com

(c) 2012 Cancer Research UK

Keywords: germ cell tumour; inhibin B; late effects; paternity; spermatogenesis; testicular cancer

In testicular cancer (TC) survivors, spermatogenesis may be compromised either due to the cancer treatment or by factors related to the aetiology of TC (Wohlfahrt-Veje et al, 2009). Fertility is a concern for many TC survivors, and among those who have tried to father children following their cancer treatment conception and paternity rates of $49-82 \%$ have been reported (Spermon et al, 2003; Huyghe et al, 2004; Brydøy et al, 2005; Huddart et al, 2005; Matos et al, 2010).

Spermatogenesis is preferably assessed by sperm samples or testicular biopsies. Endocrinological measures may yield additional information (Islam and Trainer, 1998; Andersson et al, 2004) and are often tested in the initial evaluation of cancer survivors whose fertility is of concern. Follicle stimulating

\footnotetext{
*Correspondence: Dr M Brydøy;

E-mail: marianne.brydoy@helse-bergen.no

Received 16 May 2012; revised 19 September 2012; accepted 21 September 2012
}

hormone (FSH), secreted by the pituitary gland, and inhibin B, a product of Sertoli cells, are considered endocrine markers of spermatogenesis (Islam and Trainer, 1998; Pierik et al, 2003). Serum (s)-inhibin B has been proposed to be a better marker of spermatogenesis than s-FSH (Jensen et al, 1997; Pierik et al, 2003; Mabeck et al, 2005), but based on the literature it is uncertain whether s-inhibin B gives sufficient additional information to s-FSH (Bohring et al, 2002; Andersson et al, 2004), to encourage its use in the initial evaluation of male cancer survivors with possibly impaired fertility.

Although markers of spermatogenesis have been addressed in several series of TC survivors with at least 100 cases (Lampe et al, 1997; Gerl et al, 2001; Eberhard et al, 2004; Bahadur et al, 2005; Huddart et al, 2005; Nuver et al, 2005; Gandini et al, 2006; Wiechno et al, 2007; Brydøy et al, 2010), only some include sperm parameters (Lampe et al, 1997; Eberhard et al, 2004; Bahadur et al, 2005; Gandini et al, 2006; Brydøy et al, 2010), all treatment modalities (Eberhard et al, 2004; Huddart et al, 2005), or concentrate on observations 5 years or more after treatment 
(Huddart et al, 2005; Nuver et al, 2005; Brydøy et al, 2010). Information on inhibin B is particularly sparse (Nuver et al, 2005; Romerius et al, 2010). Little is known about the inter-relationship between post-treatment endocrine markers of spermatogenesis, sperm counts, and paternity in TC survivors (Huddart et al, 2005).

The primary aim of this study was to assess sperm counts (millions per $\mathrm{ml}$ ), s-FSH, and s-inhibin B according to treatment in long-term TC survivors. A secondary aim was to study in what manner the endocrinological markers reflected sperm counts and, specifically, whether s-inhibin B in this situation added appreciable information to s-FSH alone. Finally, we explored associations between sperm counts, endocrinological markers, and achieved paternity following TC treatment.

\section{MATERIALS AND METHODS}

\section{Population and study design}

This study was part of a national multi-centre follow-up survey conducted during 1998-2002 by five collaborating units as described previously (Brydøy et al, 2005). Briefly, all men aged 18-75 years who were treated for unilateral germ cell TC in Norway in 1980 through 1994 were identified. Overall, 1814 eligible TC survivors were invited, and $1462(81 \%)$ participated in the survey, which included a mailed questionnaire and an outpatient clinical examination with laboratory tests. The study sample for this report consists of 1191 men (Supplementary Figure S1, online only), excluding participants older than 65 years $(n=70)$, those with missing hormone and sperm data $(n=158)$, men using androgen replacement therapy $(n=36)$, or having documented hyperprolactinaemia ( $>1000 \mathrm{mIUl}^{-1} ; n=6$; Islam and Trainer, 1998; Mohr et al, 2005).

Data regarding histology, Royal Marsden Hospital system staging (Peckham et al, 1979), treatment, and relapse were retrieved from the patients' medical records. The Committee for Medical Research Ethics of the Southern Health Region of Norway approved the study, and all participants gave written informed consent.

\section{Treatment}

Treatment principles of TC applied in Norway in 1980-1994 are described previously (Brydøy et al, 2005). Men treated with chemotherapy mostly received cisplatin (Cis)-based combinations with bleomycin and vinblastine or etoposide (BEP). Some patients with metastases were treated with carboplatin-based chemotherapy only $(n=24)$ or in addition to Cis-based chemotherapy $(n=8)$. Carboplatin was not used as an adjuvant in seminoma stage I. Infradiaphragmatic radiotherapy (RT) was mostly administered to seminoma patients by dog-leg or L-fields, or in some $(n=39)$ by para-aortic fields. The radiation dose was gradually reduced from $36-40$ to $25.2-27 \mathrm{~Gy}$.

The TC survivors were, in the present study, allocated to four groups according to their post-orchiectomy treatment including any relapse treatment as follows: (1) surgery only (surveillance or retroperitoneal lymph node dissection (RPLND); Surgery), (2) RT only (RT); (3) chemotherapy with a cumulative Cis dose $\leqslant 850 \mathrm{mg}$, or any carboplatin-based treatment, if Cis was not applied, with or without RPLND or RT (Cis $\leqslant 850 \mathrm{mg}$ ); and (4) chemotherapy with a cumulative Cis dose $>850 \mathrm{mg}$, with or without RPLND or RT (Cis $>850 \mathrm{mg}$ ). The cut-off point $(850 \mathrm{mg}$ ) was chosen to approximately differentiate between standard four cycles or less, and more than four cycles.

\section{Laboratory assessments}

As part of the follow-up visit, non-fasting blood samples were drawn by venipuncture between 0800 and $1200 \mathrm{~h}$ in the majority of patients. The s-FSH was analysed in fresh serum, based on commercial immunoassay technology with similar reference ranges at each of the five hospital laboratories, and values $\geqslant 12 \mathrm{IUl}^{-1}$ were considered elevated. The co-efficient variation (CV) was $<8 \%$. The s-inhibin B was assessed at one institution only, in serum samples $(n=441)$ stored at $-70^{\circ} \mathrm{C}$, until it was analysed in January 2007. An ELISA Kit (Diagnostic Systems Laboratories Inc., Webster, TX, USA) with a lower detection limit of $7 \mathrm{ngl}^{-1}$ was used. The CV was $<10 \%$. As published reference levels are not uniform (Jensen et al, 1997; Andersson et al, 2004; Sikaris et al, 2005; Myers et al, 2009), we used 80 and $140 \mathrm{ngl}^{-1}$ when grouping s-inhibin B values into a categorical variable (Jensen et al, 1997; Mahmoud et al, 1998; Pierik et al, 1998; van Casteren et al, 2009; Romerius et al, 2010).

Sperm counts (millions per $\mathrm{ml}$ ) were assessed at two units ( $n=342,42 \%$ of the eligible participants at these centres). The samples were delivered during or in proximity with the follow-up visit. Oligozoospermia was defined as $<15$ millions per $\mathrm{ml}$, and samples with no visible sperm were classified as azoospermic (World Health Organization, 2010). The recently updated WHO lower reference level of 15 millions per $\mathrm{ml}$ corresponds to the fifth centile in fertile men whose partners had a time to pregnancy (TTP) $\leqslant 12$ months (Cooper et al, 2010).

\section{Post-treatment paternity}

Data regarding attempts at conception and achieved paternity following TC treatment were retrieved from the questionnaire (Brydøy et al, 2005). Men who became fathers by pre-treatment cryopreserved semen were not included in the 'post-treatment paternity' group. Male partners of couples who received other post-treatment assistance with reproduction were included if fresh semen was used. Female fertility issues were not specifically addressed. Men who reported dry ejaculation were excluded from the analyses testing associations between markers of spermatogenesis and post-treatment paternity.

\section{Statistical analyses}

Kruskal-Wallis test (exact using Monte Carlo method), Student's $t$-test or one way ANOVA were used for group comparisons of continuous data, and exact $\chi^{2}$-, Kruskal-Wallis or Mann-Whitney (exact using Monte Carlo method) tests were used for categorical data. The s-FSH was skewed and log-transformed before analyses. Non-parametric methods were used for analyses of sperm counts and s-inhibin B. A s-inhibin B:FSH ratio was calculated as s-inhibin $\mathrm{B}\left(\mathrm{ngl}^{-1}\right)$ : s-FSH $\left(\mathrm{IU} 1^{-1}\right)$.

Linear regression analysis was used in multivariate testing of s-FSH, whereas tobit censored linear regression was applied for s-inhibin B because of the lower limit of detection $\left(7 \mathrm{ngl}^{-1}\right.$; Tobin, 1958). For s-FSH, the analysis was performed on the logarithmic value, and reported values are the exponentially transformed regression co-efficients. In addition to treatment, age at follow-up and self-reported cryptorchism (at least one undescendent testis at birth), were included as covariates (Perheentupa and Huhtaniemi, 2009; Wohlfahrt-Veje et al, 2009). Bootstrapping did not show any substantial problems with these models. A proportional odds ordinal logistic regression model was used in multivariate testing of sperm counts with five levels of sperm counts (azoospermia, Few visible sperm-1. 1.1-9.9, 10-14.9 and $\geqslant 15$ millions per $\mathrm{ml}$ ), including treatment, age, follow-up time, and cryptorchism. The assumption of proportional odds was checked (Harrell, 2001). To compare the two chemotherapy groups, the multivariate analyses were repeated using Cis $<850 \mathrm{mg}$ as reference.

Spearman's correlation was used for assessing correlations between endocrinological markers and sperm counts. To explore the positive predictive values (PPVs) for sperm counts of $s-F S H$ and s-inhibin B, we used specified cut-off levels previously 
reported to predict oligo- (s-inhibin $\mathrm{B}<80 \mathrm{ngl}^{-1}$ and s-FSH $>$ $\left.10 \mathrm{IUl}^{-1}\right)$ and azoospermia $\left(<50 \mathrm{ngl}^{-1}\right.$ and $>10.9 \mathrm{IUl}^{-1}$, respectively; Jensen et al, 1997; Romerius et al, 2010). As oligozoospermia was defined as $<20$ millions per $\mathrm{ml}$ in these reports, we also report the results for this prior definition of oligozoospermia (Cooper et al, 2010).

The data were analysed by the SPSS 17.0 package (SPSS Inc., Chicago, IL, USA) and $\mathrm{R}$ (The $\mathrm{R}$ Foundation for Statistical Computing, Vienna, Austria). All tests were two-sided, and $P$-values $<0.05$ were considered significant.

\section{RESULTS}

\section{Study population}

The interval between orchiectomy and follow-up among the 1191 men forming the study population was a median of 11 (range 4-22) years. Inhibin and sperm counts were assessed in subgroups where the interval from orchiectomy to sampling was a median of 11 (range 5-21) years for inhibin and 9 (5-20) years for sperm counts. Clinical characteristics including treatment are described in Supplementary Table S1 (online only). There were no significant differences regarding treatment group or age at orchiectomy and follow-up between the study sample and the remaining invited men below 65 years $(n=533$, data not shown).

\section{Endocrinological markers of spermatogenesis}

The geometric mean of s-FSH was 10.9 (Table 1). Overall, $42 \%$ had elevated s-FSH $\left(\geqslant 12 \mathrm{IUl}^{-1}\right)$, varying from $30 \%$ in the Surgery group to $75 \%$ in the Cis $>850 \mathrm{mg}$ group $(P<0.001$; Figure $1 \mathrm{~A})$. In the Cis $>850 \mathrm{mg}$ group, one out of three had s-FSH values above twice the upper normal level $\left(\geqslant 24 \mathrm{IU}^{-1}\right)$. According to the linear regression model, the two chemotherapy groups $(P<0.001)$, but not the RT group, had significantly higher s-FSH than the Surgery group. The Cis $>850 \mathrm{mg}$ group had $89 \%$ higher levels of s-FSH compared with the Surgery group (Table 2), and 56\% higher $\mathrm{s}$-FSH levels than the Cis $\leqslant 850 \mathrm{mg}$ group $(P<0.001)$.

The median s-inhibin B level was $57 \mathrm{ng} \mathrm{l}^{-1}$ (Table 1). Only $10 \%$ had values above $140 \mathrm{ngl}^{-1}$, and in the Cis $>850 \mathrm{mg}$ group $60 \%$ had levels below the detection limit (Figure 1B). Both chemotherapy groups $(P=0.031$ and $<0.001)$, but not the RT group, had significantly lower s-inhibin B values than the Surgery group in the multivariate model (Table 2). The s-inhibin B was significantly lower in the Cis $>850 \mathrm{mg}$ than the Cis $\leqslant 850 \mathrm{mg}$ group $\left(-42 \mathrm{ngl}^{-1}, P=0.006\right)$.

\section{Sperm counts}

Overall, 193 (56\%) had normospermia ( $\geqslant 15$ millions per $\mathrm{ml}$ ), 98 (29\%) oligozoospermia, and $51(15 \%)$ had azoospermia. Normospermia varied with treatment from $65 \%$ in the Surgery group to $29 \%$ in the Cis $>850 \mathrm{mg}$ group, and azoospermia from 6 to $43 \%$ (Figure 1C).

In the multivariate model, the two chemotherapy groups (OR $0.54-0.18$ ), but not the RT group (OR 0.76 ), had significantly lower sperm counts compared with the Surgery group $(P<0.001$ (Cis $>850 \mathrm{mg}$ ), $P=0.04 \quad$ (Cis $\leqslant 850 \mathrm{mg}$ ) and $P=0.37 \quad$ (RT); Figure 2). The Cis $>850 \mathrm{mg}$ group also had significantly lower sperm counts than the Cis $\leqslant 850 \mathrm{mg}$ group $(P=0.014)$.

Table I Hormone values and sperm counts according to treatment group ${ }^{\mathrm{a}}$

\begin{tabular}{|c|c|c|c|c|c|c|}
\hline & $\begin{array}{l}\text { Surgery } \\
(n=232)\end{array}$ & $\begin{array}{c}\text { RT } \\
(n=485)\end{array}$ & $\begin{array}{c}\text { Cis }=850 \mathrm{mg} \\
(n=38 \mathrm{I})\end{array}$ & $\begin{array}{c}\text { Cis }>850 \mathrm{mg} \\
\quad(n=93)\end{array}$ & $\begin{array}{c}\text { Total } \\
(n=1191)\end{array}$ & $P$-value \\
\hline $\begin{array}{l}\text { s-FSH, geometric mean (range), } I \cup I^{-1} \\
\text { s-Inhibin B, median (range), ngI } I^{-1} \\
\text { Sperm count, median (range), millions per ml }\end{array}$ & $\begin{array}{l}9.6(2.8-60.9) \\
70(<7-203) \\
30(0-293)\end{array}$ & $\begin{aligned} 10.3 & (1.9-86.5) \\
62 & (<7-256) \\
24 & (0-283)\end{aligned}$ & $\begin{array}{l}\mid 1.5(0.5-64.4) \\
4 \mid(<-27 \mid) \\
\mid 8(0-480)\end{array}$ & $\begin{aligned} 16.9 & (1.3-66.3) \\
<7 & (<7-211) \\
\mid & (0-98)\end{aligned}$ & $\begin{array}{c}10.9(0.5-86.5) \\
57(<7-271) \\
24(0-480)\end{array}$ & $\begin{array}{r}<0.001^{\mathrm{b}} \\
<0.001^{\mathrm{c}} \\
0.001^{\mathrm{c}}\end{array}$ \\
\hline
\end{tabular}

Abbreviations: ANOVA = analysis of variance; $\mathrm{Cis}=$ cisplatin; FSH = follicle stimulating hormone; s = serum; RT = radiotherapy. ${ }^{\mathrm{a}} \mathrm{s}$-Inhibin $\mathrm{B}$ available in $44 \mathrm{I}$ cases. Sperm counts available in 342 cases. ${ }^{b}$ One-way ANOVA (performed on the log-transformed value due to skewness). 'Kruskal-Wallis test.
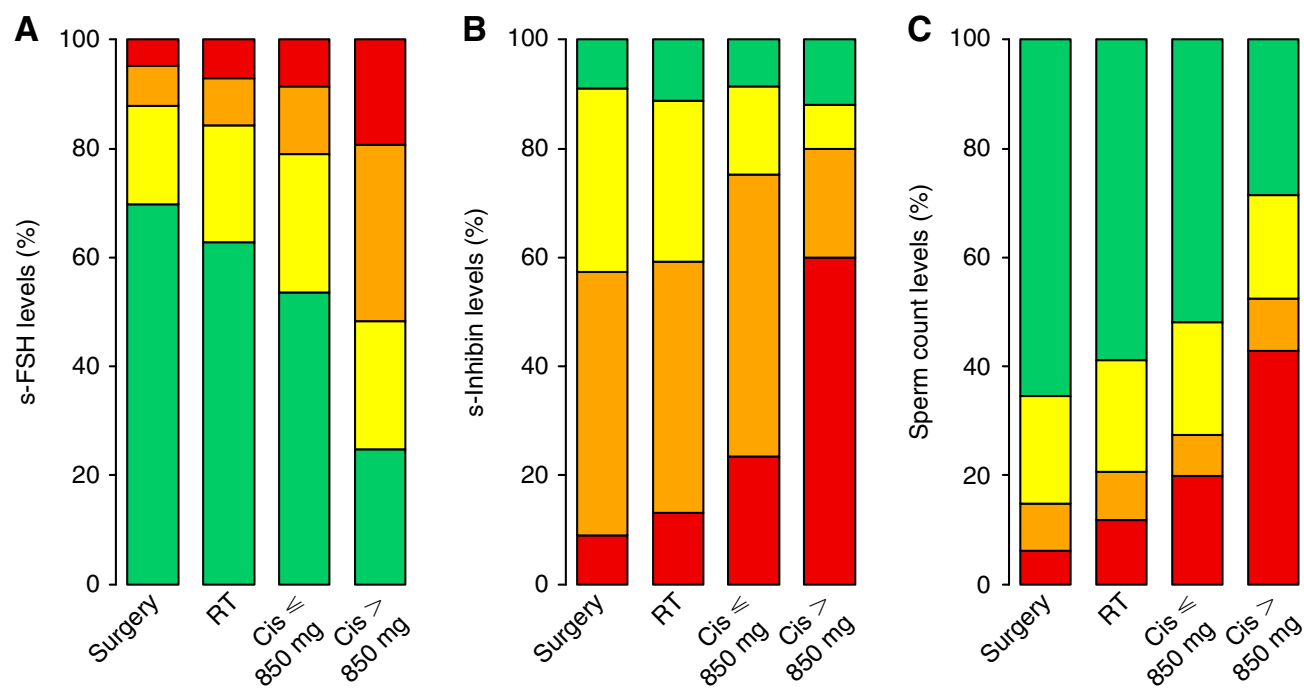

Figure I Fraction of men with grouped variables of s-FSH $(\mathbf{A})$, s-inhibin B $(\mathbf{B})$, and sperm counts $(\mathbf{C})$ according to treatment. The colour range illustrates increasing pathological levels from normal (green) to most pathological (red). (A) For s-FSH $\left(\left.\mathrm{IUI}\right|^{-1}\right.$ ): green $<12$, yellow $12-23.9$, orange 24-36, red $\geqslant 36$. (B) For s-inhibin B $\left(\mathrm{ngl}^{-1}\right)$ : green $\geqslant 140$, yellow 80.0 1 -139.9, orange 7-80, red $<7$, and (C) for sperm counts (millions per ml): green normospermia $(\geqslant 15.0)$, yellow oligozoospermia (2.0-14.9), orange oligozoospermia (few visible sperm- I.9), and red azoospermia. $(P<0.001$ for s-FSH and s-inhibin B, $P=0.00$ I for sperm counts, Kruskal-Wallis test, exact using Monte Carlo method). 
Table 2 Variations in s-FSH (\%) and s-inhibin B (absolute values) with 95\% Cl according to age, follow-up time, treatment group, and cryptorchism

\begin{tabular}{|c|c|c|c|c|c|c|}
\hline & \multicolumn{3}{|c|}{ s-FSH } & \multicolumn{3}{|c|}{ s-Inhibin B } \\
\hline & $\begin{array}{c}\text { Increase } \\
(\%)^{\mathbf{a}}\end{array}$ & $95 \% \mathrm{Cl}$ & $P$-value & $\begin{array}{l}\text { Regression } \\
\text { co-efficient }{ }^{b}\end{array}$ & $95 \% \mathrm{Cl}$ & $P$-value \\
\hline Age (I0-year interval) & 22 & 16,27 & $<0.001$ & -15 & $-21,-8$ & $<0.001$ \\
\hline Follow-up time (10-year interval) & -1 & $-10,9$ & 0.9 & 5 & $-10,19$ & 0.5 \\
\hline Treatment & & & $<0.001$ & & & $<0.001$ \\
\hline $\mathrm{Cis} \leqslant 850 \mathrm{mg}$ & 21 & 9,34 & $<0.001$ & -19 & $-36,-2$ & 0.031 \\
\hline Cis $>850 \mathrm{mg}$ & 89 & 61,121 & $<0.001$ & -61 & $-90,-32$ & $<0.001$ \\
\hline Cryptorchism & & & $<0.001$ & & & 0.6 \\
\hline No & Reference & & & Reference & & \\
\hline Yes & 24 & 11,37 & & -5 & $-22,12$ & \\
\hline
\end{tabular}

Abbreviations: $\mathrm{Cl}=$ confidence interval; $\mathrm{Cis}=$ cisplatin; $\mathrm{FSH}=$ follicle stimulating hormone; $\mathrm{RT}=$ radiotherapy. ${ }^{\mathrm{a}} \mathrm{On}$ the basis of linear regression analyses, the analysis was performed on the logarithmic value of s-FSH; numbers stated as \% are the exponentially transformed regression co-efficients. ${ }^{b}$ On the basis of tobit censored linear regression, the regression co-efficient corresponds to change in absolute values of s-inhibin $\mathrm{B}\left(\mathrm{ngl}^{-1}\right)$.

Age, follow-up time, and cryptorchism were non-significant $(P=0.7, P=0.13$, and $P=0.07$, respectively).

\section{Relations between sperm counts, hormones, and post-treatment paternity}

There was a moderate correlation between sperm counts $v s$ s-FSH, s-inhibin $\mathrm{B}$, and the s-inhibin $\mathrm{B}: \mathrm{FSH}$ ratio, with correlation co-efficients of $-0.500,0.455$, and -0.524 , respectively (all $P<0.001$ ). The correlation between s-FSH and s-inhibin $\mathrm{B}$ was $-0.656(P<0.001)$.

The vast majority of men with azoospermia had elevated s-FSH and undetectable or low s-inhibin B levels (Figure 3). However, five had normal s-FSH and s-inhibin B levels of approximately or above $80 \mathrm{ngl}^{-1}$, possibly indicating obstructive azoospermia in some. The majority of men with normospermia had normal or only slightly elevated s-FSH levels, in some contrast to s-inhibin B, which was $<80 \mathrm{ngl}^{-1}$ in more than half of these men.

The endocrinological markers could not reliably predict oligoor azoospermia. For oligozoospermia, the PPV for s-inhibin B $<80 \mathrm{ngl}^{-1}$ was $52 \%$ and for s-FSH $>10 \mathrm{IUl}^{-1}$ was $64 \%$. When combined, the PPV increased to $73 \%$. For counts $<20$ millions per $\mathrm{ml}$, the PPV was slightly higher $(59 \%, 69 \%$, and $78 \%$, respectively). For azoospermia, the PPV for s-inhibin B $<50 \mathrm{ngl}^{-1}$ was $32 \%$, for s-FSH $>10.9 \mathrm{IUl}^{-1}$ was $36 \%$, and $57 \%$ when combined.

Overall, 486 men $(41 \%)$ reported attempts at conceiving a child following TC treatment. At follow-up, 66\% (320 out of 486) had become post-treatment fathers without using pre-treatment banked semen (missing data in one). When men reporting dry ejaculation were excluded $(n=46), 70 \%$ (308 out of 439 ) had been successful in their attempts. However, 28 reported that the couple had received some kind of medical assistance with reproduction. Post-treatment paternity varied significantly according to treat-

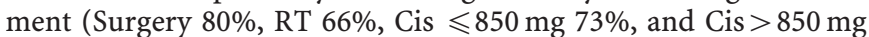
$42 \% ; P=0.001)$. The men treated with the highest doses of chemotherapy were thus about half as likely to succeed in their attempts than men treated with surgery only, whereas the paternity rate following more limited chemotherapy was considerably closer to the rate observed in the Surgery group.

The s-FSH, s-inhibin B, and sperm counts all varied significantly with paternity outcome (Table 3). Among men with normal s-FSH, $79 \%$ had achieved paternity compared with $23 \%$ if grossly elevated s-FSH $\left(\geqslant 36 \mathrm{IUl}^{-1}\right)$. Paternity rate was doubled among men with s-inhibin B levels $>140 \mathrm{ngl}^{-1}(83 \%)$ compared with undetectable levels $\left(<7 \mathrm{ngl}^{-1} ; 41 \%\right)$. In men with oligozoospermia (visible sperm-14.9 millions per $\mathrm{ml}$ ), $71 \%$ had achieved paternity. Four men recorded with post-treatment paternity had azoospermia at follow-up. Three of them also had elevated s-FSH $\left(13-42 \mathrm{IU} \mathrm{l}^{-1}\right)$ and low s-inhibin B $\left(\leqslant 25 \mathrm{ngl}^{-1}\right)$. The interval between the birth of their first child and follow-up was $7-16$ years, allowing time for intercurrent episodes that further might have compromised spermatogenesis.

\section{DISCUSSION}

In this large cohort of long-term TC survivors, spermatogenesis was significantly impaired by all assessed markers in both chemotherapy groups, but not in the RT group when compared with the Surgery group. Among those who provided a semen sample, $44 \%$ had oligo- or azoospermia. The s-FSH, s-inhibin B, and sperm counts assessed at follow-up were all associated with post-treatment paternity.

To our knowledge, this is the largest study performed, evaluating long-term effects on spermatogenesis in TC survivors, and the first to report and relate sperm counts and the endocrinological markers s-FSH and s-inhibin B within the same men. The population-based cohort, long follow-up, and the possibility to compare different treatment groups are strengths of the study. Limitations include the cross-sectional study design, with only one assessment per man. In men treated with two to four cycles of BEP, the sperm counts $(n=71)$ and s-FSH results $(n=316)$ were included in a previous publication (Brydøy et al, 2010). Paternity has previously been described in detail (Brydøy et al, 2005), and are therefore only briefly reported here.

In line with previous studies, spermatogenesis was significantly impaired in the Cis $>850 \mathrm{mg}$ group when compared with the Surgery group (Hansen et al, 1990; Palmieri et al, 1996). However, spermatogenesis, as evaluated by all three assessed measures, was also significantly impaired in the Cis $\leqslant 850 \mathrm{mg}$ group. This is in contrast to most previous reports from smaller studies among TC survivors treated with up to four chemotherapy cycles (Nijman et al, 1985; Aass et al, 1991; Pont et al, 1996). Elevated s-FSH and/ or low s-inhibin B have, however, been reported 5 years or more following chemotherapy in more recent studies, in which the chemotherapy doses were not specified (Huddart et al, 2005; Nuver et al, 2005).

Interestingly, no significant impairment for any of the spermatogenic markers was found following RT compared with the Surgery group in multivariate analyses. This is supported by 
similar non-significant results for s-FSH in the study by Huddart et al (2005). The long follow-up in these studies has likely yielded sufficient time to repair (Hansen et al, 1990). Shielding of the remaining testicle during radiation has probably also been an important factor, as probability and time to recovery of spermatogenesis are dose-dependent (Petersen et al, 1998).

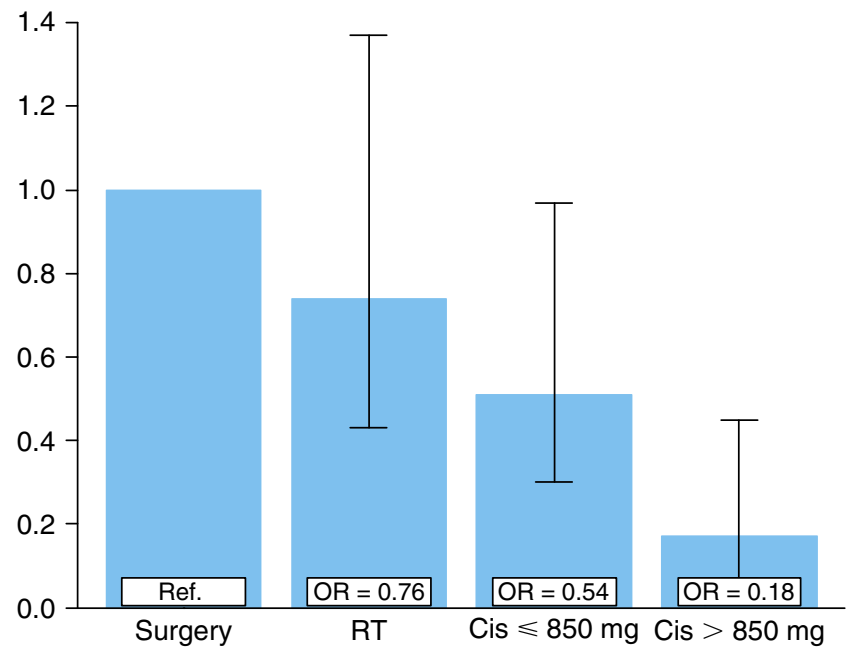

Figure 2 Odds ratios for increasing levels of sperm counts according to treatment group (overall $P=0.003$ compared with the Surgery group: $P<0.00$ I (Cis $>850 \mathrm{mg}$ ), $P=0.04$ (Cis $\leqslant 850 \mathrm{mg}$ ), and $P=0.37$ (RT)). Bars indicate $95 \%$ confidence intervals. In the proportional odds ordinal logistic regression model, sperm counts were grouped in five categories (azoospermia, few visible sperm to I million per $\mathrm{ml}$, I.I-9.9, I0-|4.9, and $\geqslant 15$ millions per $\mathrm{ml}$ ). The model was adjusted for age at follow-up, follow-up time, and self-reported cryptorchism (all non-significant).
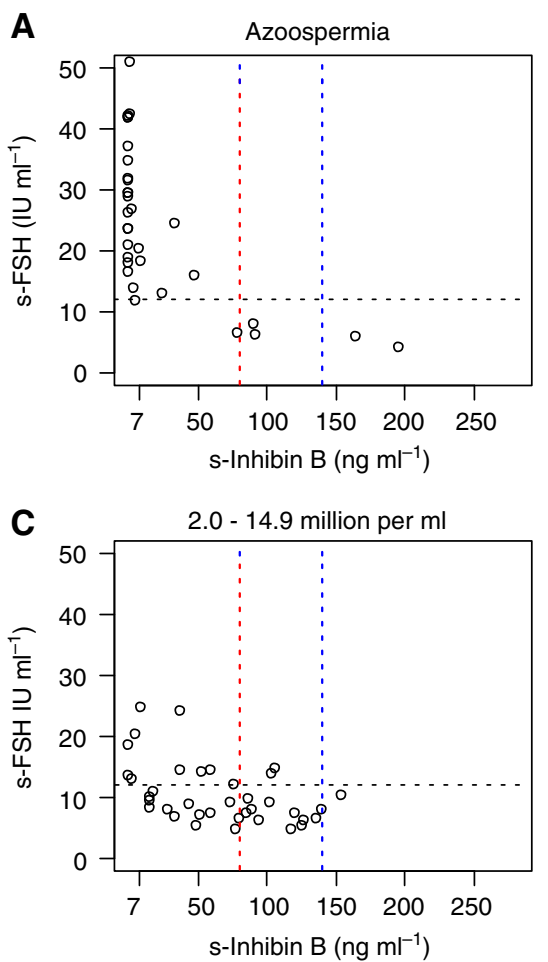

Although long-term spermatogenesis seem to be largely restored following RT, a prolonged period of recovery, the first years following treatment, may impair fertility during a more limited reproductive period of the couple, and thus reduce the chance of becoming a father (Huyghe et al, 2004; Brydøy et al, 2005).

Table 3 s-FSH, s-inhibin B, and sperm counts (millions per $\mathrm{ml}$ ) at follow-up by post-treatment paternity ${ }^{\mathrm{a}}$

\begin{tabular}{|c|c|c|c|}
\hline & \multicolumn{2}{|c|}{$\begin{array}{c}\text { Achieved } \\
\text { post-treatment paternity }\end{array}$} & \multirow[b]{2}{*}{$P$-value ${ }^{b}$} \\
\hline & Yes $(n=308)$ & No $(n=|3|)$ & \\
\hline $\begin{array}{l}\text { s-FSH, IUI-1, } N(\%) \\
\quad<\mid 2.0 \\
I 2.0-23.9 \\
24.0-35.9 \\
\geqslant 36.0 \\
\text { Geometric mean, } \mid \mathrm{UI}^{-1}\end{array}$ & $\begin{array}{r}223(79 \%) \\
69(60 \%) \\
13(46 \%) \\
3(23 \%) \\
8.7\end{array}$ & $\begin{array}{c}60(21 \%) \\
46(40 \%) \\
15(54 \%) \\
10(77 \%) \\
12.7\end{array}$ & $<0.001$ \\
\hline $\begin{array}{l}\text { s-Inhibin } B, n^{-1} \text {, N (\%) } \\
\quad<7.0 \\
7.0-79.9 \\
80.0-139.9 \\
\geqslant 140.0 \\
\text { Median }\left(\left.\mathrm{ng}^{\mathrm{c}}\right|^{-1}\right)\end{array}$ & $\begin{array}{l}7(41 \%) \\
52(70 \%) \\
40(82 \%) \\
15(83 \%) \\
78\end{array}$ & $\begin{aligned} & 10(59 \%) \\
& 22(30 \%) \\
& 9(18 \%) \\
& 3(17 \%) \\
& 57\end{aligned}$ & 0.003 \\
\hline $\begin{array}{l}\text { Sperm counts, millions per } \mathrm{m} \\
0 \\
\text { Visible-1.9 } \\
2.0-14.9 \\
\geqslant 15.0 \\
\text { Median (millions per } \mathrm{ml} \text { ) }\end{array}$ & $\begin{array}{l}(\%)^{d} \\
4(18 \%) \\
9(56 \%) \\
21(81 \%) \\
77(78 \%) \\
33\end{array}$ & $\begin{array}{r}18(82 \%) \\
7(44 \%) \\
5(19 \%) \\
22(22 \%) \\
4\end{array}$ & $<0.001$ \\
\hline
\end{tabular}

Abbreviations: FSH = Follicle stimulating hormone. ${ }^{a}$ Among 439 men without dry ejaculation who reported attempts at conception. ' $M a n n-W h i t n e y$ (exact using Monte Carlo method). 'Available in 158 cases. ${ }^{\mathrm{d}}$ Available in 163 cases.
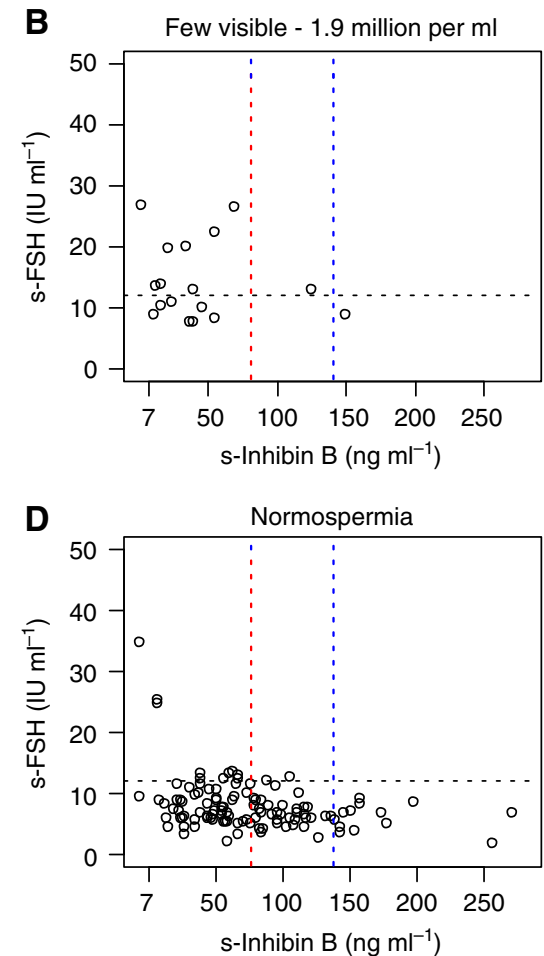

Figure 3 The s-inhibin B and s-FSH according to levels of sperm counts. Each circle represents one individual of the 199 participants, where all three measures were available. Horizontal black lines represents s-FSH $|2| \mathrm{UII}^{-1}$ and separate normal from elevated values. Vertical lines represent s-inhibin B of 80 (red) and $\mid 40 \mathrm{ng}^{-1}$ (blue). 
Following surgery only, $65 \%$ had normospermia and $6 \%$ azoospermia, compared with about $90 \%$ and $1 \%$, respectively, in the general population (Cooper et al, 2010; Romerius et al, 2010). This difference may reflect an inherent testicular defect related to aetiological factors for TC (Wohlfahrt-Veje et al, 2009) and the consequence of having only one testicle. Jacobsen et al (2001) reported a higher frequency of azoospermia (13\%) 2 years following orchiectomy only. Compared with the results for sperm counts in the RT and Cis $\leqslant 850 \mathrm{mg}$ groups, Bahadur et al (2005) observed a similar or slightly lower prevalence of azoospermia (12\%) and oligozoospermia (38\%) following gonadotoxic treatment for TC (not further specified. Others report azoospermia to be less prevalent (Eberhard et al, 2004; Gandini et al, 2006). In the Cis $>850 \mathrm{mg}$ group, $43 \%$ had azoospermia, very similar to that reported by Petersen et al (1994) in their high-dose group (47\%). This also corresponds well with the prognostic model for prediction of recovery to at least oligozoospermia defined by Lampe et al (1997) who described an estimated probability of $\sim 60 \%$ recovery 10 years after $>4$ cycles of Cis-based chemotherapy.

The observed s-inhibin B levels are considerably lower than that reported among the proven fertile men (Jensen et al, 1997; Andersson et al, 2004; Sikaris et al, 2005; Myers et al, 2009) and in the general population (Andersson et al, 2004). They also seem lower than that reported by Nuver et al (2005) in the TC survivors. They did, however, also report significantly lower levels following chemotherapy (median $63 \mathrm{ngl}^{-1}$ ) compared with surgery only $\left(125 \mathrm{ngl}^{-1}\right)$, as well as healthy controls $\left(212 \mathrm{ngl}^{-1}\right)$. Male inhibin $B$ has mainly been assessed for research purposes, and uniform reference intervals are lacking (Jensen et al, 1997; Andersson et al, 2004; Sikaris et al, 2005; Myers et al, 2009). The cut-off levels applied in this report have previously been reported to discriminate competent from impaired spermatogenesis evaluated by testicular biopsies (140 $\mathrm{ngl}^{-1}$; Pierik et al, 1998) and normospermia from oligozoospermia $(<20$ millions per $\mathrm{ml}$ ) in ejaculates (80 $\mathrm{ngl}^{-1}$; Jensen et al, 1997; Mahmoud et al, 1998). On the basis of a large study, Jørgensen et al (2010) recently suggested $150 \mathrm{ng}^{-1}$ as a relevant cut-off value for epidemiological studies, where lower levels may indicate subfertility and impaired semen quality. The s-inhibin B levels observed in this study $\left(<140 \mathrm{ngl}^{-1}\right.$ ) should thus indicate that $\sim 90 \%$ of the TC survivors have impaired semen quality. Although the sperm counts were normal in more than half of the available samples, other semen parameters that may influence quality were not assessed.

The correlations between sperm counts, s-inhibin B, and s-FSH were similar or slightly lower than that reported in men with impaired fertility, but higher than that reported in the general population (Jensen et al, 1997; Pierik et al, 1998; Andersson et al, 2004). The s-inhibin B has been proposed to be a better marker of spermatogenesis than s-FSH (Jensen et al, 1997; Pierik et al, 2003; Mabeck et al, 2005), and van Casteren et al (2010) found that s-inhibin B, but not s-FSH, significantly correlated with sperm concentration in cancer patients referred for sperm cryopreservation before treatment. We found that the correlation with sperm counts was slightly higher for s-FSH than for s-inhibin B, although highest for the s-inhibin B:FSH ratio. Some authors support combined testing for better prediction of spermatogenic function (von Eckardstein et al, 1999; Bohring et al, 2002; Andersson et al, 2004).

\section{REFERENCES}

Aass N, Fosså SD, Theodorsen L, Norman N (1991) Prediction of long-term gonadal toxicity after standard treatment for testicular cancer. Eur J Cancer 27: 1087-1091

Andersson AM, Petersen JH, Jørgensen N, Jensen TK, Skakkebaek NE (2004) Serum inhibin B and follicle-stimulating hormone levels as tools in the evaluation of infertile men: significance of adequate reference values from proven fertile men. J Clin Endocrinol Metab 89: 2873-2879
We applied cut-off levels for s-inhibin B and s-FSH that previously have been reported to be of predictive value for oligozoospermia ( $<20$ millions per $\mathrm{ml}$ ) in the general population or subfertile men (Jensen et al, 1997; Mahmoud et al, 1998), and for azoospermia in childhood cancer survivors (Romerius et al, 2010). We found the predictive abilities of these cut-off levels to be inferior to the findings in these reports (Jensen et al, 1997; Mahmoud et al, 1998; Romerius et al, 2010), but in line with a previous study for oligozoospermia (Meeker et al, 2007). Although the majority of participants with azoospermia had very low s-inhibin B and elevated s-FSH, this pattern was also seen in a few men with subnormal or normal sperm counts (Figure 3). Combined testing may thus give some indications of, but do not reliably predict, the sperm counts of TC survivors.

According to our opinion, we have not proven a definitive clinical benefit of evaluating s-inhibin B in the follow-up of TC survivors, where infertility might be a concern. There are also cost issues not further discussed here. Serum levels of luteinising hormone and testosterone are considered of limited value in the assessment of spermatogenesis (Jezek et al, 1998).

The fraction of men with achieved post-treatment paternity decreased with decreasing levels of s-inhibin B and, particularly, with increasing levels of s-FSH measured at follow-up. These associations must be interpreted with caution due to the unknown and varying interval between attempts at conceiving a child and follow-up. With normal s-FSH, 79\% had succeeded in their attempts, somewhat lower than that reported by Huddart et al (2005) (91\%). On the contrary, only about one in four of men with grossly elevated s-FSH ( $\geqslant 36$ IE) had achieved paternity. Posttreatment paternity seemed to vary less with s-inhibin B. As the 15 millions per $\mathrm{ml}$ reference value corresponds to the 5 th centile in men whose partners conceived within a year of attempts, it is of interest that $71 \%$ of the men with oligozoospermia (excluding azoospermia) had become fathers. The TTP is, however, unknown, and some had received assistance with reproduction. Four men with azoospermia at follow-up reported post-treatment paternity. Although it is possible that some men were not the biological father, cautions should be made with such speculations as only one sample was analysed, and other incidents affecting sperm counts may have occurred between conception and sperm analysis years later (Islam and Trainer, 1998; Petersen and Hansen, 1999).

In conclusion, RT had no long-term effects on the assessed markers of spermatogenesis, whereas chemotherapy had. At present, the routine evaluation of s-inhibin B has not shown significantly better predictive value compared with FSH and other traditional fertility evaluations in the initial fertility assessment of TC survivors.

\section{ACKNOWLEDGEMENTS}

Laboratory personnel at each of the participating hospitals are gratefully acknowledged for analysing serum hormones and sperm specimens. This work was supported by the Norwegian Health and Rehabilitation Fund (grant number 1998/207), the Western Norway Regional Health Authority, and the Norwegian Cancer Society.

Supplementary Information accompanies the paper on British Journal of Cancer website (http://www.nature.com/bjc)
Bahadur G, Ozturk O, Muneer A, Wafa R, Ashraf A, Jaman N, Patel S, Oyede AW, Ralph DJ (2005) Semen quality before and after gonadotoxic treatment. Hum Reprod 20: 774-781

Bohring C, Schroeder-Printzen I, Weidner W, Krause W (2002) Serum levels of inhibin B and follicle-stimulating hormone may predict successful sperm retrieval in men with azoospermia who are undergoing testicular sperm extraction. Fertil Steril 78: 1195-1198 
Brydøy M, Fosså SD, Klepp O, Bremnes RM, Wist EA, Wentzel-Larsen T, Dahl O (2005) Paternity following treatment for testicular cancer. J Natl Cancer Inst 97: 1580-1588

Brydøy M, Fosså SD, Klepp O, Bremnes RM, Wist EA, Wentzel-Larsen T, Dahl O (2010) Paternity and testicular function among testicular cancer survivors treated with two to four cycles of cisplatin-based chemotherapy. Eur Urol 58: 134-140

Cooper TG, Noonan E, von Eckardstein S, Auger J, Baker HW, Behre HM, Haugen TB, Kruger T, Wang C, Mbizvo MT, Vogelsong KM (2010) World Health Organization reference values for human semen characteristics. Hum Reprod 16: 231-245

Eberhard J, Ståhl O, Giwercman Y, Cwikiel M, Cavallin-Ståhl E, Lundin KB, Flodgren P, Giwercman A (2004) Impact of therapy and androgen receptor polymorphism on sperm concentration in men treated for testicular germ cell cancer: a longitudinal study. Hum Reprod 19: 1418-1425

Gandini L, Sgro P, Lombardo F, Paoli D, Culasso F, Toselli L, Tsamatropoulos P, Lenzi A (2006) Effect of chemo- or radiotherapy on sperm parameters of testicular cancer patients. Hum Reprod 21: 2882-2889

Gerl A, Muhlbayer D, Hansmann G, Mraz W, Hiddemann W (2001) The impact of chemotherapy on Leydig cell function in long term survivors of germ cell tumors. Cancer 91: 1297-1303

Hansen SW, Berthelsen JG, von der Maase H (1990) Long-term fertility and Leydig cell function in patients treated for germ cell cancer with cisplatin, vinblastine, and bleomycin versus surveillance. J Clin Oncol 8: 1695-1698

Harrell Jr FE (2001) Regression Modeling Strategies. Springer-Verlag New York Inc.: New York

Huddart RA, Norman A, Moynihan C, Horwich A, Parker C, Nicholls E, Dearnaley DP (2005) Fertility, gonadal and sexual function in survivors of testicular cancer. Br J Cancer 93: 200-207

Huyghe E, Matsuda T, Daudin M, Chevreau C, Bachaud JM, Plante P, Bujan L, Thonneau P (2004) Fertility after testicular cancer treatments: results of a large multicenter study. Cancer 100: 732-737

Islam N, Trainer PJ (1998) The hormonal assessment of the infertile male. Br J Urol 82: 69-75

Jacobsen KD, Theodorsen L, Fossa SD (2001) Spermatogenesis after unilateral orchiectomy for testicular cancer in patients following surveillance policy. J Urol 165: 93-96

Jensen TK, Andersson AM, Hjollund NH, Scheike T, Kolstad H, Giwercman A, Henriksen TB, Ernst E, Bonde JP, Olsen J, McNeilly A, Groome NP, Skakkebaek NE (1997) Inhibin B as a serum marker of spermatogenesis: correlation to differences in sperm concentration and follicle-stimulating hormone levels. A study of 349 Danish men. J Clin Endocrinol Metab 82: 4059-4063

Jezek D, Knuth UA, Schulze W (1998) Successful testicular sperm extraction (TESE) in spite of high serum follicle stimulating hormone and azoospermia: correlation between testicular morphology, TESE results, semen analysis and serum hormone values in 103 infertile men. Hum Reprod 13: 1230-1234

Jørgensen N, Liu F, Andersson AM, Vierula M, Irvine DS, Auger J, Brazil CK, Drobnis EZ, Jensen TK, Jouannet P, Overstreet JW, Redmon JB, Sparks A, Toppari J, Wang C, Skakkebæk NE, Swan SH (2010) Serum inhibin-b in fertile men is strongly correlated with low but not high sperm counts: a coordinated study of 1,797 European and US men. Fertil Steril 94: 2128-2134

Lampe H, Horwich A, Norman A, Nicholls J, Dearnaley DP (1997) Fertility after chemotherapy for testicular germ cell cancers. J Clin Oncol 15: 239-245

Mabeck LM, Jensen MS, Toft G, Thulstrup M, Andersson M, Jensen TK, Giwercman A, Olsen J, Bonde JP (2005) Fecundability according to male serum inhibin B - a prospective study among first pregnancy planners. Hum Reprod 20: 2909-2915

Mahmoud AM, Comhaire FH, Depuydt CE (1998) The clinical and biologic significance of serum inhibins in subfertile men. Reprod Toxicol 12: 591-599

Matos E, Skrbinc B, Zakotnik B (2010) Fertility in patients treated for testicular cancer. I Cancer Surviv 4: 274-278

Meeker JD, Godfrey-Bailey L, Hauser R (2007) Relationships between serum hormone levels and semen quality among men from an infertility clinic. J Androl 28: 397-406

Mohr BA, Guay AT, O'donnell AB, McKinlay JB (2005) Normal, bound and nonbound testosterone levels in normally ageing men: results from the Massachusetts Male Ageing Study. Clin Endocrinol (Oxf) 62: 64-73
Myers GM, Lambert-Messerlian GM, Sigman M (2009) Inhibin B reference data for fertile and infertile men in Northeast America. Fertil Steril 92: 1920-1923

Nijman JM, Schraffordt Koops H, Kremer J, Willemse PH, Sleijfer DT, Oldhoff J (1985) Fertility and hormonal function in patients with a nonseminomatous tumor of the testis. Arch Androl 14: 239-246

Nuver J, Smit AJ, Wolffenbuttel BH, Sluiter WJ, Hoekstra HJ, Sleijfer DT, Gietema JA (2005) The metabolic syndrome and disturbances in hormone levels in long-term survivors of disseminated testicular cancer. J Clin Oncol 23: 3718-3725

Palmieri G, Lotrecchiano G, Ricci G, Spiezia R, Lombardi G, Bianco AR, Torino G (1996) Gonadal function after multimodality treatment in men with testicular germ cell cancer. Eur J Endocrinol 134: 431-436

Peckham MJ, Barrett A, McElwain TJ, Hendry WF (1979) Combined management of malignant teratoma of the testis. Lancet 2: 267-270

Perheentupa A, Huhtaniemi I (2009) Aging of the human ovary and testis. Mol Cell Endocrinol 299: 2-13

Petersen PM, Hansen SW (1999) The course of long-term toxicity in patients treated with cisplatin-based chemotherapy for non-seminomatous germ-cell cancer. Ann Oncol 10: 1475-1483

Petersen PM, Hansen SW, Giwercman A, Rorth M, Skakkebaek NE (1994) Dose-dependent impairment of testicular function in patients treated with cisplatin-based chemotherapy for germ cell cancer. Ann Oncol 5: 355-358

Petersen PM, Skakkebaek NE, Giwercman A (1998) Gonadal function in men with testicular cancer: biological and clinical aspects. APMIS 106: 24-34

Pierik FH, Burdorf A, de Jong FH, Weber RF (2003) Inhibin B: a novel marker of spermatogenesis. Ann Med 35: 12-20

Pierik FH, Vreeburg JT, Stijnen T, de Jong FH, Weber RF (1998) Serum inhibin B as a marker of spermatogenesis. J Clin Endocrinol Metab 83: 3110-3114

Pont J, Albrecht W, Postner G, Sellner F, Angel K, Holtl W (1996) Adjuvant chemotherapy for high-risk clinical stage I nonseminomatous testicular germ cell cancer: long-term results of a prospective trial. J Clin Oncol 14: 441-448

Romerius P, Ståhl O, Moell C, Relander T, Cavallin-Ståhl E, Wiebe T, Giwercman YL, Giwercman A (2010) High risk of azoospermia in men treated for childhood cancer. Int J Androl 34: 69-76

Sikaris K, McLachlan RI, Kazlauskas R, de KD, Holden CA, Handelsman DJ (2005) Reproductive hormone reference intervals for healthy fertile young men: evaluation of automated platform assays. J Clin Endocrinol Metab 90: 5928-5936

Spermon JR, Kiemeney LA, Meuleman EJ, Ramos L, Wetzels AM, Witjes JA (2003) Fertility in men with testicular germ cell tumors. Fertil Steril 79: 1543-1549

Tobin J (1958) Estimation of relationships for limited dependent variables. Econometrica 26: 24-37

van Casteren NJ, Boellaard WP, Romijn JC, Dohle GR (2010) Gonadal dysfunction in male cancer patients before cytotoxic treatment. Int J Androl 33: 73-79

van Casteren NJ, van der Linden GH, Hakvoort-Cammel FG, Hahlen K, Dohle GR, van den Heuvel-Eibrink MM (2009) Effect of childhood cancer treatment on fertility markers in adult male long-term survivors. Pediatr Blood Cancer 52: 108-112

von Eckardstein S, Simoni M, Bergmann M, Weinbauer GF, Gassner P, Schepers AG, Nieschlag E (1999) Serum inhibin B in combination with serum follicle-stimulating hormone (FSH) is a more sensitive marker than serum FSH alone for impaired spermatogenesis in men, but cannot predict the presence of sperm in testicular tissue samples. J Clin Endocrinol Metab 84: 2496-2501

Wiechno P, Demkow T, Kubiak K, Sadowska M, Kaminska J (2007) The quality of life and hormonal disturbances in testicular cancer survivors in Cisplatin era. Eur Urol 52: 1448-1454

Wohlfahrt-Veje C, Main KM, Skakkebaek NE (2009) Testicular dysgenesis syndrome: fetal origin of adult reproductive problems. Clin Endocrinol (Oxf) 71: 459-465

World Health Organization (2010) WHO Laboratory Manual for the Examination and Processing of Human Semen. 5th edn. WHO Press: Geneva

This work is published under the standard license to publish agreement. After 12 months the work will become freely available and the license terms will switch to a Creative Commons Attribution-NonCommercial-Share Alike 3.0 Unported License. 